\title{
INHALTSVERZEICHNIS DES ZWEITEN BANDES
}

1. Von der Renaissance des Peripatos im 1. Jh. v. Chr. bis auf Alexander von Aphrodisias

H. J. Drossaart Lulofs (Amsterdam): Das Prooimion von $\Pi \varepsilon \rho \grave{\varphi} \varphi v \tau \tilde{\omega} v \ldots \ldots \ldots \ldots$

Jutta Kollesch (Berlin/DDR): Galens Auseinandersetzung mit der aristotelischen Samenlehre . . . . . . . .

Vivian Nutton (London): Galen's philosophical testament: 'On my own opinions' . . . . . . . . . . . .

Albrecht Dihle (Heidelberg): Die Schicksalslehren der Philosophie in der Alten Kirche . . . . . . . . . . .

Alexander von Aphrodisias

Pierluigi Donini (Triest): Aristotelismo e indeterminismo in Alessandro di Afrodisia . . . . . . . . . . . . . . .

H. J. Blumenthal (Liverpool): Alexander of Aphrodisias in the later Greek commentaries on Aristotle's De Anima . . . . . . . . . . . . . . . . . . . 90 90

Pierre Thillet (Paris): Alexandre d'Aphrodise et la poésie 107

3. Griechische Exegeten in der Periode der Herrschaft des Neuplatonismus

Paul Henry $\dagger($ Gent): Apories orales de Plotin sur les Catégories d'Aristote . . . . . . . . . . . . . . . . 120

Horst Seidl (Nijmegen): Aristoteles' Lehre von der vón-

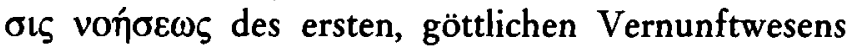
und ihre Darstellung bei Plotin . . . . . . . . . . . . 157

Salomo Pines (Jerusalem): Some distinctive metaphysical conceptions in 'Themistius' commentary on Book Lambda and their place in the history of philosophy .

H.D.Saffrey (Paris): Comment Syrianus, le maître de l'école néoplatonicienne d'Athènes, considérait-il Aristote? . . . . . . . . . . . . . . . 205 
Leonardo Tarán (New York): Syrianus and PseudoAlexander's commentary on Metaph. E-N . . . . . . . 215

Pierre Aubenque (Paris): Zur Entstehung der pseudo-aristotelischen Lehre von der Analogie des Seins . . . . . 233

Ilsetraut Hadot (Paris): La division néoplatonicienne des écrits d'Aristote

4. Lateinische und byzantinische Exegeten

Sten Ebbesen (Kopenhagen): Boethius as an Aristotelian scholar . . . . . . . . . . . . . . . . . . . . 286

James Shiel (Univ. of Sussex): The Greek copy of Porphyrios' Isagoge used by Boethius . . . . . . . . . . 312

Antony C.Lloyd (Liverpool): The Aristotelianism of Eustratios of Nicaea . . . . . . . . . . . . . . . . . . 341

Linos G. Benakis (Athen): Grundbibliographie zum Aristoteles-Studium in Byzanz . . . . . . . . . . 352

5. Aristoteles bei den Arabern

Gotthard Strohmaier (Berlin/DDR): ,Von Alexandrien nach Bagdad' - eine fiktive Schultradition . . . . . . 380 Miklós Maróth (Budapest): Aristoteles und Ibn Khaldūn. Zur Entstehung einer aristotelischen Geschichtsphilosophie . . . . . . . . . . . . . . . . 390

6. Aristoteles in der griechischen Überlieferung

Jean Irigoin (Paris): Dédoublement et simplification de lettres dans la tradition d'Aristote (Du ciel II, Métaphysique Z) . . . . . . . . . . . . . . .

Paul Canart (Città del Vaticano): Manuscrits d'Aristote et de ses commentateurs sur papier occidental ancien . 418

7. Aristoteles im lateinischen Mittelalter

Gudrun Vuillemin-Diem (Köln): La traduction de la Métaphysique d'Aristote par Guillaume de Moerbeke et son exemplaire grec: Vind.phil.gr. $100(J) \ldots . . . .434$ 
Bernd Schneider (Berlin): Bemerkungen zum Aristoteles Latinus: Spuren einer Revision der Politikübersetzung des Wilhelm von Moerbeke . . . . . . . . . . . . . . . 487

Fritz Wagner (Berlin): Aristoteles-Erwähnungen im Mittelalter ................

8. Aristoteles in der Neuzeit: Renaissance bis 20. Jh.

Charles B.Schmitt $\dagger$ (London): Auctoritates, Repertorium, Dicta, Sententiae, Flores, Thesaurus, and Axiomata: Latin Aristotelian Florilegia in the Renaissance .

Paul Richard Blum (Berlin): Sentiendum cum paucis, loquendum cum multis: Die aristotelische Schulphilosophie und die Versuchungen der Naturwissenschaften bei Melchior Cornaeus SJ

Theodor Ebert (Erlangen): Entelechie und Monade. Bemerkungen zum Gebrauch eines aristotelischen $\mathrm{Be}$ griffs bei Leibniz . . . . . . . . . . . . . . . . 560

Johannes Irmscher (Berlin/DDR): Adamantios Korais: Aristoteles-Rezeption in der Epoche der griechischen Erhebung von $1821 \ldots \ldots \ldots \ldots$

Klaus Oehler (Hamburg): Eine bisher unveröffentlichte englische Übersetzung der ersten vier Kapitel der Aristotelischen Kategorienschrift von Charles Sanders Peirce aus dem Jahre 1864 . . . . . . . . . . . . . . 590

Jacques Brunschwig (Paris): Un ennemi d'Aristote à $\mathrm{Pa}$ ris: Léon Brunschvicg . . . . . . . . . . . . . . 596

Christian Hünemörder (Hamburg): Zur Nachwirkung des Aristoteles bei den Biologen im 19. und 20. Jahrhundert . . . . . . . . . . . . . . .

Indices. Von Jürgen Wiesner . . . . . . . . . . . . . 632

Index locorum: Aristoteles

1. Corpus Aristotelicum . . . . . . . . . . . . . 634

2. Schriften außerhalb des Corpus . . . . . . . . 642

Index locorum: Auctores praeter Aristotelem . . . . . . 643 
Index codicum et librorum impressorum

1. Handschriften

(A) Hss. allgemein: Papier, Provenienzen, lokale Schreibstile, Hss.-Wanderungen . . . . . . . . 672

(B) Einzelne Kodizes: arabische, griechische, lateinische, syrische, verlorene Hss. . . . . . . . . . . 672 Peirce Papers . . . . . . . . . . . . . . . 675

2. Editionen vor 1800: Drucker und Verleger . . . 675

Index nominum

1. Persönlichkeiten, Schulen, Strömungen ․ . . . 677

2. Orte und Länder . . . . . . . . . . . . . . . 692

Corrigenda zu Band I . . . . . . . . . . . . . 693 